\title{
Painful hip instability due to a partial tear of the iliofemoral ligament and labral injury following a cycling accident
}

\begin{abstract}
Patients commonly present with generalized hip pain in the presence of normal radiographs, posing a diagnostic dilemma for physicians. The hip is the essential and central component of movement between the torso and lower extremities and is integral to proper performance in almost all sports. Instability occurs with defined acute events as an episode of dislocation or subluxation. Atraumatic instability may be difficult to diagnose because of the absence of an acute onset and the broad differential diagnosis of hip pain. MRI coronal images provide iliofemoral ligament evaluation. MRI specifically of cam-type impingement shows insufficient head-neck offset and rapid cartilage loss over the anterosuperior margin of the dome. Evaluation of the femoral head will demonstrate an osseous deformity at the anterolateral aspect of the femoral head-neck junction, often with intraosseous ganglion cysts adjacent to the anterior capsule and thickening of the iliofemoral ligament. We report a case of iliofemoral ligament injury, an entity often unsuspected in the initial clinical evaluation and diagnosis. Although uncommon, it should be investigated in imaging tests, because when present, we can justify a patient's symptomatology, as documented in the present case.
\end{abstract}

Keywords: ligaments, articular, hip joint, magnetic resonance imaging
Volume 2 Issue I - 2018

\author{
Márcio Luís Duarte,' Daniel Pires Penteado \\ Ribeiro, ${ }^{2}$ Thaís Nogueira Dantas, ${ }^{2}$ Laura \\ Burni Pereira Gomes, ${ }^{3}$ Angelo Augusto \\ Perrone, ${ }^{2}$ José Luiz Masson de Almeida \\ Prado, ${ }^{2}$ Luiz Carlos Donoso Scoppetta ${ }^{2}$ \\ 'Department of Radiology, Brazil \\ 2Radiology, Hospital São Camilo, Brazil \\ ${ }^{3}$ Faculty of Medical Sciences of Minas Gerais, Brazi
}

Correspondence: Márcio Luís Duarte,WEBIMAGEM, São Paulo, Brazil, Email marcioluisduarte@gmail.com

Received: November 27, 2017 | Published: January 29, 2018
Abbreviations: MRI, magnetic resonance imaging; ILFL, iliofemoral ligament; ISFL, ischiofemoral ligament; PFL, pubofemoral ligament; CLH, capsular ligaments of the hip; IBILFL, inferior band of the iliofemoral ligament; SBILFL, superior band of the iliofemoral ligament; ESWT, extracorporeal shock wave therapy

\section{Introduction}

Patients commonly present with generalized hip pain in the presence of normal radiographs, posing a diagnostic dilemma for physicians. ${ }^{1}$ The hip is the essential and central component of movement between the torso and lower extremities and is integral to proper performance in almost all sports. ${ }^{2}$ Thus, hip pain in the athlete, whether recreational or elite, presents a critical challenge to performance. ${ }^{2}$ Depending on the study and sport, the hip accounts for $3-18 \%$ of all sports-related injuries. ${ }^{2}$ Pain and dysfunction from athletic hip injuries cause significant morbidity, including the greatest time lost from sports compared to other lower extremity injuries. ${ }^{2}$ The etiology of mechanical hip pain can be either intraarticular or extra-articular, leading to an incredibly diverse list of differential diagnoses.

\section{Case presentation}

41 year old man complained about pain in the right hip for 10 days. It refers cycling for six days/week for 6-10 hrs/week and fall from his bike 90 days ago, with progressive worsening of the pain, leading to functional impairment including walk making it impossible to practice sports and even the orthopedic physical examination. It denies previous surgeries and cycling practicing 5 to 6 days a week. MRI shows injury of the superolateral aspect of the acetabular labrum, acetabular, femoral head and neck edema, joint effusion and partial tear of the iliofemoral ligament (Figures 1-3). The patient was submitted to conservative treatment, since he denied surgical therapy, with ESWT and hip muscle strength therapy for three months, returning to cycling with lower intensity and frequency ( 2 hours/ week), but without pain.

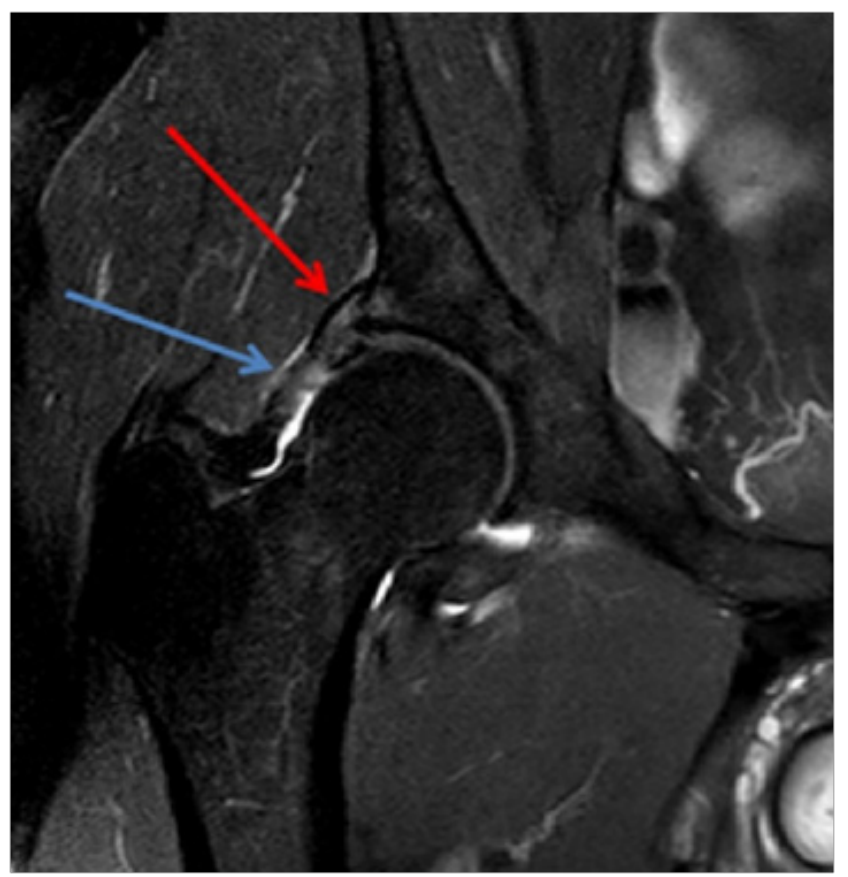

Figure I MRI in T2 SPIR sequence in the coronal section demonstrating labral lesion (red arrow) and partial rupture of the iliofemoral ligament (blue arrow). 


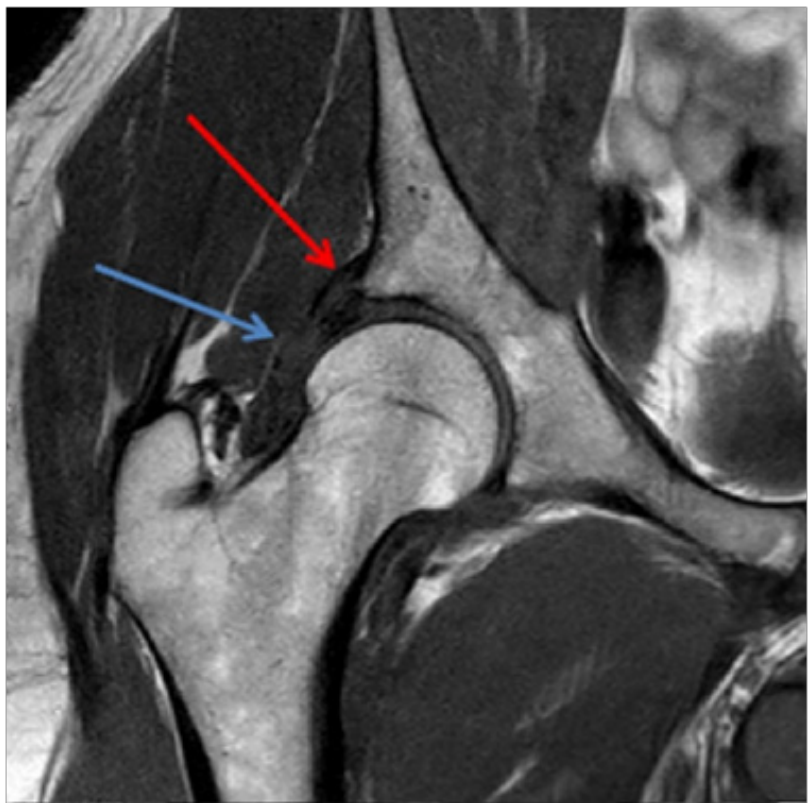

Figure $2 \mathrm{MRI}$ in TI sequence in the coronal section demonstrating labral lesion (red arrow) and partial rupture of the iliofemoral ligament (blue arrow).

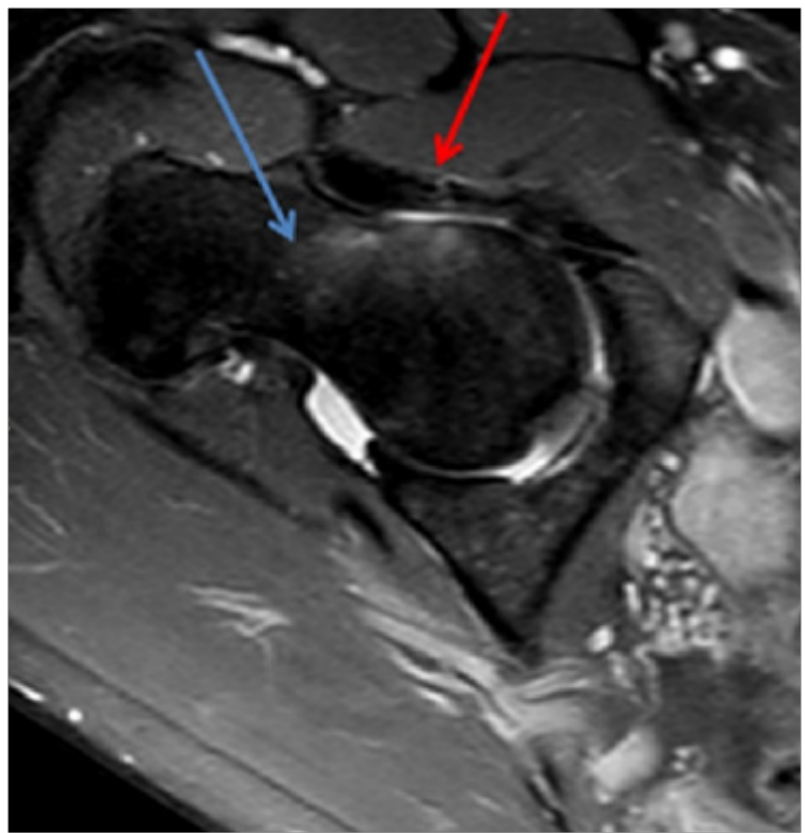

Figure $3 \mathrm{MRI}$ in T2 SPIR sequence in the axial section demonstrating femoral neck edema (blue arrow) and partial rupture of the iliofemoral ligament (red arrow).

\section{Discussion}

The hip joint possesses an anatomic configuration that allows both mobility and stability. ${ }^{3}$ There are three extra capsular ligaments, which are the ILFL, ISFL and, $\mathrm{PFL}^{4}$ they are major structures that stabilize the hip joint. ${ }^{5,6}$ The ILFL is the strongest one and is also designated the Y ligament or ligament of Bigelow, is shaped like the inverted letter $Y$ and reinforces the anterior aspect of the capsule. ${ }^{3,4,6,7}$ The ILFL can be divided into two components: the inferior band, also termed the medial arm and the superior band, also termed the lateral arm or iliotrochanteric ligament. ${ }^{3}$ The CLH have an important role in providing stability to the hip by restricting motion beyond the normal range. ${ }^{3}$ During extension, the IBILFL is under the greatest tension..$^{3,5}$ During flexion, all of the CLH are relaxed. ${ }^{3,5}$ Abduction is restricted by the PFL which is loose with adduction and in the neutral position. ${ }^{3,5}$ During adduction, the postero-superior portion of the capsule is tense. ${ }^{3,5}$ During external rotation, the SBILFL is the most important restrictor, and the IBILFL and PFL are also under tension but to a lesser extent, especially with the hip extended. ${ }^{3,5}$ The ISFL is slack with the hip externally rotated. ${ }^{3}$ During internal rotation, the ISFL is under tension, and all the anterior ligaments are lax. ${ }^{3}$ The causes of hip instability can be divided into traumatic and atraumatic. ${ }^{3}$

I. Traumatic instability occurs with defined acute events as an episode of dislocation or subluxation. ${ }^{3}$

II. Atraumatic instability may be difficult to diagnose because of the absence of an acute onset and the broad differential diagnosis of hip pain..$^{3,7}$

III. Established causes include ${ }^{3,7}$

IV. Patients with generalized joint laxity or with an underlying connective tissue disorder.

V. Patients with developmental dysplasia of the hip.

VI. Athletes participating in sports with repetitive forced rotational movements and axial loading.

VII. In athletes, repetitive microtraumatic injuries cause increased tension in the joint capsule that can lead to painful labral injury, capsular redundancy, and subsequent micro-instability.,

MRI coronal images provide iliofemoral ligament evaluation. MRI specifically of cam-type impingement shows insufficient headneck offset and rapid cartilage loss over the anterosuperior margin of the dome. ${ }^{1}$ Evaluation of the femoral head will demonstrate an osseous deformity at the anterolateral aspect of the femoral headneck junction, often with intraosseous ganglion cysts adjacent to the anterior capsule and thickening of the iliofemoral ligament. ${ }^{1}$ Insufficiency of the iliofemoral ligament can reportedly lead to subtle instability and possibly lead to hip pain. ${ }^{7}$ If both the acetabular labrum and iliofemoral ligament are torn, they should be surgically repaired to restore native hip translation and rotation. ${ }^{7}$ However, ESWT has proven to be an effective and safe noninvasive treatment option for musculoskeletal system disorders. ${ }^{8}$

\section{Acknowledgements}

None.

\section{Conflict of interest}

The authors declare that there is no conflict of interests regarding the publication of this paper.

\section{Patient consent}

The written informed consent of the patient was obtained, for the publication of her case.

\section{References}

1. Gold SL, Burge AJ, Potter HG. MRI of Hip Cartilage. Clin Orthop Relat Res. 2012;470(12):3321-3331. 
2. Ladd LM, Blankenbaker DG, Davis KW, et al. MRI of the Hip: Important Injuries of the Adult Athlete. Curr Radiol Rep. 2014;2:51.

3. Wagner FV, Negrão JR, Campos J, et al. Capsular ligaments of the hip: anatomic, histologic and positional study in cadaveric specimens with MR arthrography. Radiology. 2012;263(1):189-198.

4. Demange MK, Kakuda CMS, Pereira CAM, et al. Influência do ligamento da cabeça do fêmur na mecânica do quadril. Acta ortop bras. 2007;15(4):187-190.

5. Hidaka E, Aoki $M$, Izumi $T$, et al. Ligament strain on the iliofemoral, pubofemoral and ischiofemoral ligaments in cadaver specimens: biomechanical measurement and anatomical observation. Clin Anat. 2014;27(7):1068-1075.
6. Chang CY, Huang AJ. MR imaging of normal hip anatomy. Magn Reson Imaging Clin N Am. 2013;21(1):1-19.

7. Myers CA, Register BC, Lertwanich $\mathrm{P}$, et al. Role of the acetabular labrum and the iliofemoral ligament in hip stability: an in vitro biplane fluoroscopy study. Am J Sports Med. 2011;39:85S-91S.

8. Schmitz C, Császár NB, Milz S, et al. Efficacy and safety of extracorporeal shock wave therapy for orthopedic conditions: a systematic review on studies listed in the PEDro database. Br Med Bull. 2015;116:115-138. 